\title{
Factors Influencing Audit Technology Acceptance by Audit Firms: A New I-TOE Adoption Framework
}

\author{
Khairina Rosli ${ }^{1}$, Paul H.P. Yeow ${ }^{2}$ and Eu-Gene Siew ${ }^{3}$ \\ ${ }^{1}$ School of Accountancy, College of Business, Universiti Utara Malaysia, Kedah, Malaysia \\ ${ }^{2}$ School of Business, Monash University, Selangor, Malaysia \\ ${ }^{3}$ School of Information Technology, Monash University, Selangor, Malaysia
}

\begin{abstract}
Many businesses are now moving to e-business and implementing computerized accounting information systems. This phenomenon has given impact to audit profession in performing IT audit, financial reports audit and tracing electronic source documents. Computer-Assisted-Auditing Techniques and Tools (CAATTs) are audit technologies that allow IT audit work to be performed efficiently, effectively and reduce audit time. However, little is known about CAATTs adoption by public audit firms. This paper presents a new paradigm of Individual-Technology-OrganizationEnvironment (I-TOE) to investigate the acceptance of CAATTs in audit firms. There are gaps that exist in prior literatures which studied CAATTs acceptance from only individual auditor views and did not deliberate on issues from both organizational and individual perspectives. Consequently, this paper contributes to extend the literature by providing a better understanding on relationship of both organizational and individual factors in foreseeing CAATTs adoption and investment. A combination of Unified Theory of Acceptance and Use of Technology 2, and TechnologyOrganization-Environment framework are used as the underlying theories. In addition to that, this paper complements the framework with new variables of technology risk, technology task fit, organization readiness and top management commitment. I-TOE framework contributes to professional audit firms that need to measure CAATTs acceptance for the advancement of audit profession. Future experimental studies may be done to provide evidence and empirically validate I-TOE framework in other domain.
\end{abstract}

Keywords: Audit Technology, CAATTs, IT Audit, Technology Acceptance.

\section{Introduction}

CAATTs are audit computer tools and techniques that are used to assist the completion of both external and internal auditing of organizations' financial reports and internal controls. CAATTs include the usage of any technology in audit, for example, electronic working papers, word processing applications, spreadsheet applications, statistical analysis software and computer application program (Braun \& Davis, 2003). CAATTs are classified into five categories: test data, integrated test facility, parallel simulation, embedded audit module and generalized audit software (Braun \& Davis, 2003). CAATTs comprise of automated tools and techniques that aid auditors to excerpt,

Copyright (C) 2012 Khairina Rosli, Paul H.P. Yeow and Eu-Gene Siew. This is an open access article distributed under the Creative Commons Attribution License unported 3.0, which permits unrestricted use, distribution, and reproduction in any medium, provided that original work is properly cited. Contact author: Khairina Rosli E-mail: khairina@uum.edu.my 
examine and evaluate logic of processed audit data. With CAATTs, auditors can also analyse extracted data and cross-examine live data in a range of databases and application software (Braun \& Davis, 2003; Debreceny, Lee, Neo \& Toh, 2005).

The level of CAATTs implementation is still minimal and not widely utilized by public accounting firms (Curtis \& Payne, 2008). Big firms have greater possibility to implement CAATTs. However, small-to-medium sized accounting firms are still struggling in CAATTs adoption. Organization's tight capital (budget) is the possible factor for low adoption of CAATTs (Curtis \& Payne, 2008). For that reason, audit firms' decision of CAATTs adoption must be based on the technological aspect, which is suitable with organizational capabilities and the demands of the changing environment. From previous literature, the study has found that there are gaps in CAATTs adoption, where it is not sufficient enough to study CAATTs acceptance from individual perspective or organization perspective separately. This is because the intention to adopt CAATTs by audit firm may be affected by individual auditors in the firm. For example, if the auditor perceives that using CAATTs technology in audit work would benefit and improve their job performance, then they would propose to the firm to adopt CAATTs.

In addition, individual auditor's intention to adopt CAATTs might also be affected by the audit firm's policy. For example, the support from top management or mandatory use of CAATTs imposed by audit firm. While many previous studies investigate CAATTs intention adoption behaviour only from individual perspective, this paper presents the adoption of CAATTs from both individual and organizational point of views. It is important to investigate both individual and organizational contributing factors of audit firms' intentional behaviour as it is more comprehensive. Besides, human resource is likewise important to be considered in audit firms' evaluation because organizations are run by individual workforces and it is important to evaluate their acceptance of IT (Venkatesh, Morris, Davis \& Davis, 2003).

Realizing the problems and gaps in the existing literature, this paper aims to develop a comprehensive CAATTs adoption framework with a fresh paradigm that integrates all individual (I), technology (T), organization (O), and environmental (E) factors, termed as I-TOE, and to address both individual and organizational point of views.

This paper contributes to audit profession practices with a comprehensive analysis of organization's CAATTs adoption factors such as individual adoption factors, organization readiness, top management commitment, technology risk and task- fit. This research will help audit firms to build and implement organizational strategies to increase CAATTs acceptance and reduce its risks. This study also contributes to the existing literature of technology adoption with the development of new inclusive paradigm of I-TOE that integrates UTAUT and TOE framework in studying CAATTs adoption.

The remainder of this paper consist of four sections. The subsequent section brief on the background of CAATTs adoption in audit profession and next analyses previous literatures on CAATTs adoption. Then, the paper discusses Unified Theory of Acceptance and Use of Technology (UTAUT) and Technology-Organization-Environment (TOE) framework to develop and present the hypotheses for I-TOE conceptual framework of CAATTs adoption for organization. Finally, the paper provides a brief conclusion and opportunity for future research.

\section{Background}

The law requires organizations' financial reports and internal control to be audited periodically to ensure that the reports are true and fairly presented. Audit works has become more challenging as many organizations opt to implement e-business and utilize sophisticated computerized accounting information systems, such as the 
use of Enterprise Resource Planning and Electronic Data Interchange. Traditional auditing such as auditing around the computer to check printed documents manually, has progressively changed to auditing with the computer and auditing through the computer. Auditor are now moving to audit the information technology/ information systems (IT/IS) used in business operations. Therefore, integrating IT in audit, i.e. CAATTs will enhance the audit firms' competitiveness and effectiveness of audit services (IFAC, 2011).

Performing audit procedures efficiently and effectively are important to auditors in ensuring financial statements are free from fraud and comply with the standards of accounting and auditing such as the International Standards of Auditing (ISAs) by International Auditing and Assurance Standard Board (IIASB). Auditors are also responsible to ensure the effectiveness of an organization's internal control under the compliance of Section 404 of Sarbanes-Oxley Act (Janvrin, Lowe \& Bierstaker, 2009; Hall, 2004). CAATTs are audit technologies that aid in efficiency and effectiveness of audit job by automating manual audit activities (Curtis \& Payne, 2008; Braun \& Davis, 2003). Computerized audit reduces audit cost incurred and improves the audit quality and productivity (Banker, Chang \& Kao, 2002). The demand for reliable, relevant and timely audit result could be fulfilled with the help of CAATTs. Much of time consumed to perform audit tasks manually that are burdening auditors, could be lessened with the use of CAATTs. Moreover, auditor may have more time to consult clients or organizations with wider range of consultation services such as assess business risks, develop prevention controls and measure client's business performance (Bierstaker, Burnaby \& Thibodeau, 2001).

Despite the benefits of CAATTs and efforts of accounting professional bodies to help promoting the implementation of computerized audit advancement among organizations, the present adoption, perception and use of CAATTs by auditors varies considerably in different organization sizes and industries such as government, public accounting firms and financial institutions (Debreceny, et al., 2005). More than half of internal auditors in United Kingdom utilize CAATTs with less than 10\% of their hours worked. Yet, there is improvement in CAATTs usage over time, where $67 \%$ of the internal auditors increase the use of CAATTs up to 50\% (Mahzan \& Lymer, 2009). While auditors recognized the ability of CAATTs to improve audit effectiveness and efficiency, they believed they did not get the full benefits due to technical problems (Braun \& Davis, 2003). Moreover, auditors are confident with basic CAATTs task but not in more complex situations. On the contrary, in other research, some auditors who possess low level of audit IT knowledge, perceived that advanced technologies in audit as less important in audit work (Ismail \& Abidin, 2009). Characteristics of individual such as risk taker versus risk-averse also affects audit technology implementation decision (Curtis \& Payne, 2008). These previous studies, nonetheless, focus the acceptance of computerized audit from individual auditor's perception.

\section{Literature Review}

Most of the prior literatures are on CAATTs adoption by individual auditor (Mahzan \& Lymer, 2009; Braun \& Davis, 2003; Janvrin et al., 2008). Braun and Davis (2003) survey CAATTs usage and satisfaction among states governmental auditors. The results reveal that auditors acknowledged the potential benefits of CAATTs; nevertheless, they demonstrated an inferior confidence in handling the audit software applications due to their technical capabilities and CAATTs technical problems. Concerning their level of IT skills, auditors desired for CAATTs training to boost their usage confidence level and to be more satisfied in performing their job.

Pertaining to auditors' technical skills, Ismail and Abidin (2009) explore auditors' 
perceptions towards the importance of IT in audit and their IT knowledge in auditing. They found that there is a gap between auditors' perceived importance of IT and their actual levels of IT knowledge particularly in more advanced computerized audit. However, the study did not examine how audit task complexity and decision making activities affect the computerized audit usage.

Curtis and Payne (2008) case study of Big 4 audit firms revealed that communications of software usage by firm's partners have the ability to influence individual employee on new audit technology implementation. The auditors have a tendency to use new audit technology when they know that the firm's managing partner is supporting the technology usage in the firm. Besides, firm's longer-term financial plan and longer evaluation periods of audit technology also affects auditors' decision whether or not to use an audit technology. Interestingly, the study found that individual characteristic such as risk-seeking auditors are more likely to implement new technology irrespective of firm budget pressure. On the other hand, low risk preference auditor would decide to use audit technology when there are high budget pressure.

Most of the previous studies applied UTAUT as the underlying theory. For example, internal auditor motivation measured by performance expectancy, effect of externalities and facilitating conditions factors have found to be significantly influential in regards to CAATTs adoption (Mahzan \& Lymer, 2009). Social influence factor, however, was not included as the affecting reason because the studied CAATTs adoption was voluntary in practice. It is argued that if CAATTs are mandatory in organization, then social influence would impact on CAATTs adoption. Yet, the study has to be validated with more comprehensive empirical quantitative analysis due to its low data response and small number of internal auditor population covered.

\author{
Theoretical Framework to Investigate \\ External and Internal Factors of CAATTs \\ Adoption
}

\section{UTAUT}

UTAUT is a useful model in evaluating the success of newly introduced IT/IS acceptance. UTAUT also helps firms' managers to understand the new technology acceptance factors so that they could develop further strategy of improvements for their employees.

Venkatesh et al. (2003) developed the cohesive model of UTAUT that incorporates constructs from Theory of Reasoned Action, Technology of Acceptance Model, Motivational Model, Theory of Planned Behaviour, Model of Personal Computer Utilization, a combined Theory of Planned Behaviour and Technology Acceptance Model, Innovation Diffusion Theory and Social Cognitive Theory. Venkatesh et al. (2003) found that performance expectancy, effort expectancy, social influence and facilitating conditions are directly associated with behavioural intention to use a technology that consequently affect user's decision to adopt a technology. Intention to use a technology is originated from the modified concept in Technology Acceptance Model. Furthermore, intention to use a system would explain user's actual system usage. This intention has been found to be a driving factor toward individual's actual behaviour as deliberated in the Theory of Reasoned Action (Taylor \& Todd, 1995). The effects of gender, age, experience and voluntariness of use have also been found significantly associated with the eight previous models and have been validated as the moderating factors affecting the adoption factors in UTAUT. Venkatesh, Thong and $\mathrm{Xu}$ (2012) developed a new UTAUT2, extending UTAUT with the inclusion of hedonic motivation, price value and habit as the predictors of behaviour intention to use a technology. 


\section{TOE Framework}

There are other aspects that firms need to consider besides looking at individual employee factor. Technological, organizational and external environment of firms are important factors which may influence CAATTs investment decision. TOE framework (Tornatzky \& Fleischer, 1990) addresses these fundamental aspects. Technological context refers to technology characteristics and availability for firm. In the case of CAATTs adoption, audit firm has to really know the characteristics of CAATTs such as technology cost-benefit and risk before it is going to be adopted. Nevertheless, the decision whether or not to use CAATTs is determined not merely by firm perception of the technology characteristic, but also whether the technology fits with the audit task that needs to be performed. As suggested by Delone and McLean (2003), "Researchers must also consider the nature, extent, quality and appropriateness of the system use". Although a technology may be perceived as being useful and advanced, if it does not fit with audit task requirements, organization may not adopt the technology. As for CAATTs adoption, the CAATTs must fit with the audit firm's tasks in performing audit. The public auditing environment is seen as a unique setting of IT/IS acceptance decision because the decision is done on each of audit work (Curtis \& Payne, 2008).

Next, organizational context describes the organization measures such as decision making structure and communication process by top management and organization size. It could also reflect the organization's human resource and IS capabilities, organizational IT infrastructure, organization working culture and readiness towards adopting new IT innovation. Lastly, in environmental context, TOE holds that organization has to deal with its surrounding environment, such as client, competitors in industry, regulatory bodies' obligations and external pressure. As audit firms provide assurance services to its client, they are tied to audit engagement and the pressure of budgeted working hours after the client engagement is signed (Curtis \& Payne, 2008).

UTAUT and TOE frameworks would best reflect audit firms' decision makers (owner/ manager and/or supervisor) in deciding on CAATTs adoption and usage. With the integration of technology, organization and environment constructs in TOE, and UTAUT's constructs of performance expectancy, effort expectancy, social influence and facilitating conditions, it is believed that the factors influencing audit firm decision to invest in CAATTs is much more clear-cut.

\section{Research Design}

\section{Hypotheses and Conceptual Framework}

Individual Influences: Performance Expectancy, Effort Expectancy, Social Influence, Facilitating Surrounding and Hedonic Motivation

In this study, we define performance expectancy as the degree to which auditor perceives that he/ she will achieve progresses in audit work performance when using CAATTs. Performance expectancy is the strongest predictor of intention to use a system (Venkatesh et al., 2003). It is adapted from perceived usefulness, job-fit, relative advantage and outcome expectation constructs. Perceived usefulness directly influences actual use of a system. Perceived usefulness of IT/IS may derived from the IT/IS characteristic. It is found that implementation of audit software in big accounting firm reduces the time for working paper preparation. Electronic presentation of accounting information aids the audit professionals' decision-making process (Banker et al., 2002). If performance expectancy of an auditor rises, the intention to use CAATTs by the auditor would also increase. Consequently, it is posited that:

H1: Auditor's intention to use CAATTs will be influenced by performance expectancy. 
Adapted from Venkatesh et al. (2003), this research defines effort expectancy as the degree of easiness that individual auditor feels when using CAATTs. System's ease of use is found as the core motivation for management accounting technological adoption (Smith et al., 2008). Ease of use characteristic of a technology positively affects user's behavioural intention to use a system and consequently it would influence the system's actual usage (Venkatesh et al., 2003). A user would have intention behaviour to adopt a technology if he/she believes that the technology would help him/her to accomplish tasks without difficulty. In audit context, Banker et al. (2002) found that automated accounting report makes auditors' judgement process easier than manual report. Thus, it is hypothesized that:

H2: Auditor's intention to use CAATTs will be influenced by effort expectancy.

UTAUT and UTAUT2 studies found that social influence significantly affect user's behavioural intention to use a technology (Venkatesh et al., 2003). In CAATTs adoption context, this study defines social influence as the degree of encouragement from other people that influence an auditor to adopt CAATTs. Hence, it is anticipated that:

H3: Auditor's intention to use CAATTs will be affected by social influence.

Facilitating surrounding as adapted from Venkatesh et al. (2003) is defined as the degree to which auditor believes that physical facilities and technical infrastructure in public auditing firm are well provided to support auditor's technology usage. Facilitating surrounding is important measures for an effective IT adoption in common (Venkatesh et al., 2012). Studies have found that organizational infrastructure and technological support affect individual auditor's decision to use CAATTs (Janvrin et al., 2009; Mahzan \& Lymer, 2009). Hence, it is anticipated that:
H4: Auditor's intention to use CAATTs will be affected by facilitating surrounding.

UTAUT2 (Venkatesh et al., 2012) has extended UTAUT with inclusion of hedonic motivation as one of the contributing factors influencing user's intention to use a technology. Hedonic motivation is the perceived pleasure or elegant stylish feeling that an auditor feels when using CAATTs. Logically, if the auditor feels that using CAATTs in audit work is 'cool' and has a great pleasure in using CAATTs features, functions and interface, then the auditor's intention to use CAATTs would also increase. Accordingly, the following hypothesis is established:

H5: Auditor's intention to use CAATTs will be affected by hedonic motivation.

This study posits that individual auditor's intention to use CAATTs would affect audit firm's intention to adopt CAATTs. This is due to the fact that audit firms' credibility and performance depend on their employees (auditors) to accomplish audit assignment for client (Curtis \& Payne, 2008). If auditors believe that they should adopt CAATTs to help them accomplish audit investigations, they will influence audit firm's management to adopt CAATTs. Hence, it is anticipated that:

H6: Audit firm's intention to use CAATTs will be influenced by individual auditor's intention to use CAATTs.

Technological Influences: CAATTs Costbenefit, CAATTs Risk and CAATTs Task Fit

When adopting accounting software package, technology characteristic such as price, easy to use, availability of backup recovery, guidance and tutorial must be well-thoughtout (Rushinek \& Rushinek, 1995). In addition to that, cost effective use of technology is also important to be measured because it is an indicator to the performance of the technology (Tan, Teo \& Lai, 2011). Therefore, it is anticipated that: 
7 Journal of Accounting and Auditing: Research \& Practice

H7: Audit firm's intention to use CAATTs will be affected by cost-benefits of CAATTs.

All investment not only involves cost but also risks, as expenditure is incurred in exchange to a long-run benefits and return (Tiernan \& Peppard, 2004). Implementing technology could be risky as the firm may face computer threats and vulnerabilities which lead to dissatisfaction in use (Hall, 2004; Romney \& Steinbart, 2006). Improper use of CAATTs could lead to audit inaccuracy and it could affect firm's intention to use the technology. Therefore, it is anticipated that:

H8: Audit firm's intention to use CAATTs will be negatively affected by risks of CAATTs.

CAATTs' Task-technology fit is the degree of match between CAATTs technology and tasks that need to be performed in audit. Technology task fit is reflected by the interaction between task complexity requirement (non-routines, interdependence, and job title), individual abilities (training, experience, IT skills) and IT/IS functions. This study anticipates that the more CAATTs fit with audit task, the more suitable the technology will be and therefore CAATTs would be more accepted by audit firm. Prior study suggested that suitability of a system use must be considered for the system to be implemented in an organization (DeLone \& McLean, 2003). Furthermore, task and technology fit influence usage of IS (Goodhue \& Thompson, 1995). Hence, it is posited that:

H9: Audit firm's intention to use CAATTs will be affected by CAATTs task-technology fit.

\section{Organizational Influences: Size, Readiness and Top Management Commitment}

Organization's size has been frequently recognized as a precursor to technology acceptance (Zhu, Kremer \& Xu, 2003). Larger firm may have more capital and human resources to ensure that technology can be well adopted. Big four audit firms' acceptance of technology usage is higher than small and medium sized audit firms (Janvrin, Bierstaker \& Low, 2008). Hence, it is anticipated that:

H10: Audit firm's intention to use CAATTs will be affected by audit firm's size.

Firm's readiness can be depicted by the firm's financial and technical resources (Iacovou, Benbasat \& Dexter, 1995). These resources are used to promote organization's readiness by preparing the organization with technological equipment and creating working atmosphere to support technology acceptance. As asserted by Curtis and Payne (2008), if public accounting firm has a pressure on its budget, it would create a possibility of technology resistance in the firm. Readiness among public accounting firms varies in meeting new challenges. Firms that offer new services to customers are more ready for new challenges (Salleh, Rose, Kumar \& Peng, 2007). Hence, it is hypothesized that:

H11: Audit firm's intention to use CAATTs will be affected by audit firm's readiness.

Audit firm's top management commitment is the involvement and role played by person at the top management level to encourage CAATTs adoption. Salleh et al. (2007) stated that participation of top management in public accounting firm's ICT project has led to an improved decision making process for technology acquisition and implementation in the firms. In the context of technology adoption among auditors, firm's partners also play a great role in motivating their employees to adopt audit technology (Curtis \& Payne, 2008). For that reason, the following hypothesis is established:

H12: Audit firm's intention to use CAATTs will be affected by audit firm's top management commitment.

\section{Environmental Influences: Client's AIS Complexity}

Most of audit firms' clients use AIS to record, process and disseminate accounting 
information to stake holders. Client's AIS must be audited to ensure that business transactions are correctly processed and reports are accurately generated. The higher business transactions take place, the more complex client's AIS will be. Consequently, the higher complexity of client's AIS, the more necessary for audit firm to adopt CAATTs to audit the client's AIS. Therefore, this study posits that client's business complexity affects audit firm's intention to adopt CAATTs.

H13: Audit firm's intention to use CAATTs will be affected by client's AIS complexity.

Audit firm's actual usage of CAATTs is the ultimate dependent variable in this study.
This is to explain whether firm's intention to use a technology will in turn affect firm's future or actual usage of the technology. At user's level of technology usage, Venkatesh et al, (2003) and Venkatesh et al, (2012) use intention to use a technology as a predictor of actual usage of the technology. It is found that behavioural intention significantly influences actual usage. This leads to the following hypothesis:

H14: Audit firm's intention to use CAATTs will influence audit firm's actual usage of CAATTs.

Figure 1 depicts the research conceptual framework.

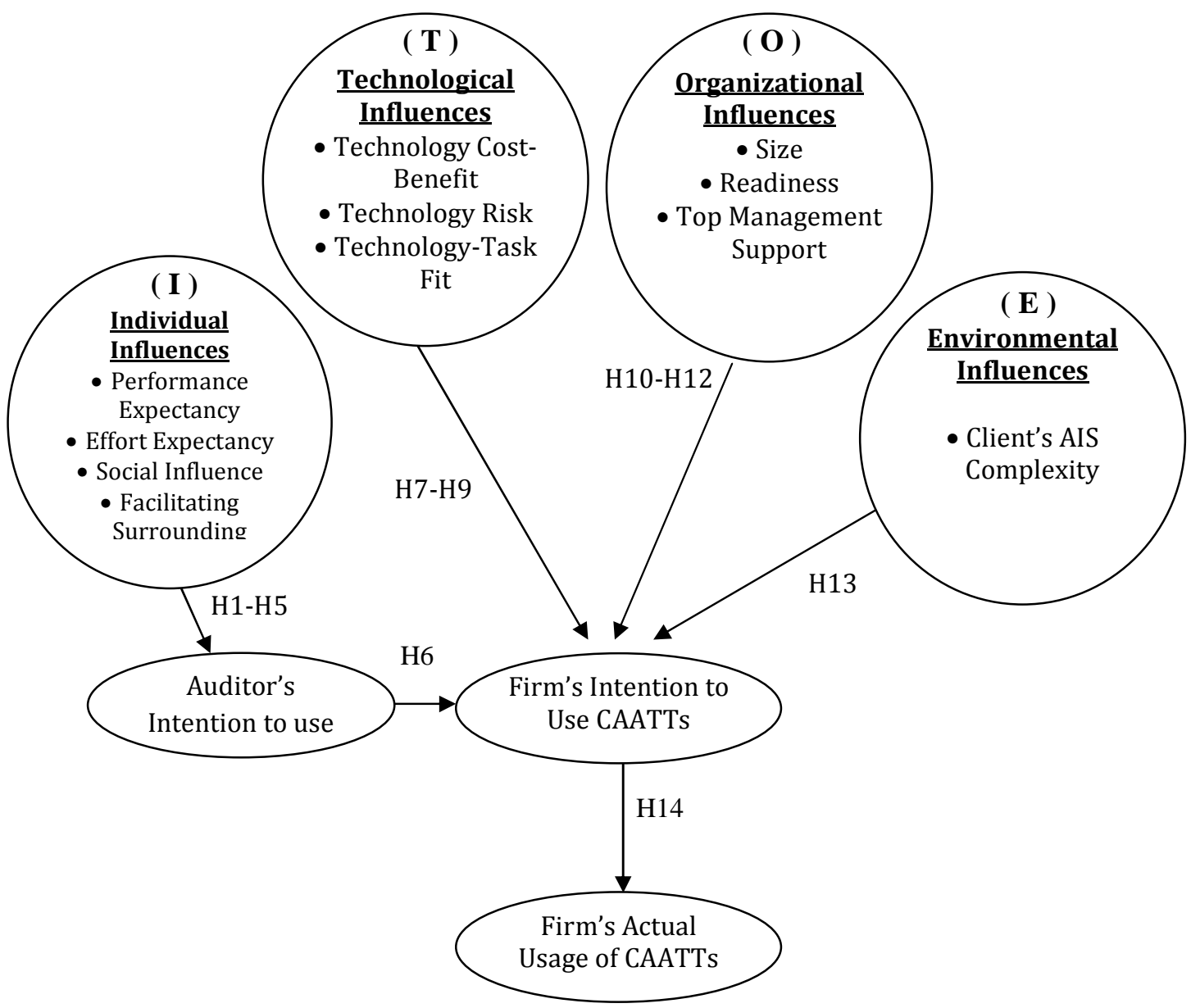

Fig 1. I-TOE Conceptual Framework of CAATTs Adoption 


\section{Discussion and Future Research}

I-TOE framework provides more comprehensive views of CAATTs adoption. Decision makers could evaluate the acceptance of new audit technology in their organization from every aspect of individual, technology, organization and external environment. It is understood that by considering only one acceptance dimension could not give sufficient assessment on technology adoption. The social nature in technology adoption among firms infers that using individual based theory is inappropriate (Parker \& Castleman, 2007). Owners, managers and supervisors are the individuals in firms that influence the adoption decision but firms are also influenced by their social environment. Depending on only one theory of either UTAUT or TOE respectively could restrict the perceptions of CAATTs adoption. By doing so, decision makers in organization could only evaluate the CAATTs investment decision from a limited perspective. For that reason, ITOE adoption framework integrates individual's performance expectancy, effort expectancy, social influence, facilitating conditions and hedonic motivation constructs of UTAUT2 and technology, organization and environment construct of TOE to complement each of the individual and organizational viewpoint. Future research may be done to provide empirical evidence and validate the I-TOE framework. Additionally, relationship between the constructs may also be further investigated.

\section{Conclusion}

This paper aims to develop a new I-TOE paradigm that contributes a comprehensive context of individual, technological, organizational and environmental to examine CAATTs adoption in public accounting firms. It is argued that acceptance of CAATTs does not merely depends on individual auditor's acceptance but also be contingent on organization's management, technological characteristics and other environment factors. Clients' AIS complexity, audit firm's readiness, top management commitment, technology cost-benefit, risk and task-fit are discussed to address the issue of CAATTs from organization viewpoint. This paper adapts UTAUT2 and TOE framework as the fundamental theory. I-TOE framework will benefit public audit firms with the antecedents that they need to deliberate in adoption of CAATTs and to predict the acceptance of CAATTs in their organization.

\section{Acknowledgment}

Authors would like to thank Associate Professor Dr. Khalid S. Soliman, anonymous reviewers and participants of $18^{\text {th }}$ IBIMA conference for their constructive comments and suggestions in improving this paper.

\section{References}

Banker, R. D., Chang, H. \& Kao, Y.- C. (2002). "Impact of Information Technology on Public Accounting Firm Productivity," Journal of Information Systems, Vol.16 (2), pp. 209-222.

Bierstaker, J. L., Burnaby P. \& Thibodeau, J. (2001). "The Impact of Information Technology on the Audit Process: An Assessment of the State of the Art and Implications for the Future," Managerial Auditing Journal, Vol. 16(3), pp.159-164.

Braun, R. L. \& Davis, H. E. (2003). “ComputerAssisted Audit Tools and Techniques: Analysis and Perspectives," Managerial Auditing Journal, Vol.18 (9), pp.725-731.

Curtis, M. B. \& Payne, E. A. (2008). "An Examination of Contextual Factors and Individual Characteristics Affecting Technology Implementation Decisions in Auditing," International Journal of Accounting Information Systems, Vol.9 (2), pp.104-121.

Debreceny, R., Lee, S. L., Neo, W. \& Toh, J. S. (2005). "Employing Generalized Audit Software in the Financial Services Sector: 
Challenges and Opportunities," Managerial Auditing Journal, Vol. 20 (6), pp.605-618.

DeLone, W. H., \& McLean, E. R. (2003). "The DeLone and McLean Model of Information Systems Success: A Ten-Year Update," Journal of Management Information Systems, Vol. 19 (4), pp.9-30.

Goodhue, D. L. \& Thompson, R. L. (1995). "Task-Technology Fit and Individual Performance," MIS Quarterly, Vol.19 (2), pp.213-236.

Hall, J. A. (2004). 'Accounting Information Systems,' United States, Thompson Learning.

Iacovou, C. L., Benbasat, I. \& Dexter, A. S. (1995). "Electronic Data Interchange and Small Organizations: Adoption and Impact of Technology," MIS Quarterly, Vol.19 (4), pp.465-485.

IFAC (2011). 'Technology and E-Business,' Guide to practice management for small-and medium sized practices, 2nd Ed, International Federation of Accountants.

Ismail, N. A \& Abidin, A. Z. (2009). "Perception towards the Importance and Knowledge of Information Technology among Auditors in Malaysia," Journal of Accounting and Taxation, Vol.1 (4), pp.61-69.

Janvrin, D., Bierstaker, J. \& Lowe, D. J. (2008). "An Examination of Audit Information Technology Use and Perceived Importance," Accounting Horizons, Vol. 22(1), pp.1-21.

Janvrin, D., Lowe, D. J., \& Bierstaker, J. L. (2009). 'Auditor Acceptance of ComputerAssisted Audit Techniques,' American Accounting Association Auditing Section 2009 Midyear Conference, Vol.54, St. Petersburg, Florida, American Accounting Association.

Mahzan, N., Lymer, A. (2009). 'Examining Adoption of Computer Assisted Audit Tools and Techniques (CAATTs): Cases of UK internal Auditors,' Proceedings of 12th International Business Information Management Association (IBIMA) Conference, Kuala Lumpur, Malaysia.

Parker, C. M. \& Castleman, T. (2007). "New Directions for Research on SME-eBusiness: Insights from an Analysis of Journal Articles from 2003 to 2006," Journal of Information Systems and Small Business, Vol. 1, pp.21-40.

Romney, M. B. \& Steinbart, P. J. (2006). Accounting Information Systems, New Jersey, Pearson Prentice Hall.

Rushinek, A. \& Rushinek, S. F. (1995). "Accounting Software Evaluation: Hardware, Audit Trails, Backup, Error Recovery and Security," Managerial Auditing Journal, Vol.10 (9).

Salleh, A., Rose, R. C., Kumar, N. \& Peng, L. C. (2007). "Readiness in Meeting Globalization Challenges: A Case of Accounting Firms in Malaysia," Journal of social Sciences, Vol. 3 (4), pp.176-184.

Smith, M., Abdullah, Z. \& Razak, R. A. (2008). "The Diffusion of Technological and Management Accounting Innovation: Malaysian Evidence," Asian Review of Accounting, Vol. 16 (3), pp.197-218.

Taylor, S. \& Todd, P. A. (1995). "Understanding Information Technology Usage: A Test of Competing Models," Information Systems Research, Vol. 6 (4), pp.144-176.

Tiernan, C. \& Peppard, J. (2004). 'Information Technology: Of Value of a Vulture?,' European Taxation, Vol.44 (12), pp.609.

Tornatzky, L. G. \& Fleischer, M., Chakrabarti, A. K. (1990). The Processes of Technological Innovation, Lexington, MA, Lexington Books.

Venkatesh, V., Morris, M. G., Davis, G. B. \& Davis, F. D. (2003). "User Acceptance of 
11 Journal of Accounting and Auditing: Research \& Practice

Information Technology: Toward a Unified View," MIS Quarterly, Vol. 27 (3), pp.425-478.

Venkatesh, V., Thong, J. Y. L. \& Xu, X. (2012). Consumer Acceptance and Use of Information Technology: Extending the Unified Theory of Acceptance and Use of Technology, Forthcoming in MIS Quarterly, Vol. 36 (1), pp.157-178.

Zhu, K., Kraemer, K. L. \& Xu, S. (2003). "EBusiness Adoption by European Firms: A Cross-Country Assessment of the Facilitators and Inhibitors," European Journal of Information Systems, Vol. 12 (4), pp.251-268. 